\title{
Appendix
}

\section{Case-study profiles}

\section{Centre for Alternative Technology}

Opened 1975

\section{Aims}

To showcase alternative technology so as to inform, inspire and enable others to utilise sustainable living practices.

\section{Internal structure}

The Centre is run by a co-operative and full-time staff (who are all paid the same wage), supplemented by both long- and short-term volunteers. The Alternative Technology Association (ATA) is CAT's supporter group. ATA has approximately 4,000 members, holds annual conferences and produces the Clean Slate magazine. The majority of CAT's income is from visitors and donations, and other revenue is raised through publications, mail orders, residential courses and consultancy. The 7-acre site houses the visitor complex, a shop and restaurant, environmental information centre, a mail order service, a consultancy, a publications department, an education department and eco-cabins.

\section{Tactics}

Although CAT is primarily a visitor centre, it also runs training courses about alternative technology, publishes a range of books, operates the eco-cabins as an educational centre for school children, provides consultancy to organisations and runs a free information service. 


\section{Friends of the Earth UK}

Formed 1971

\section{Aims}

To take action to change policies or practices that degrade the environment. In 2002 its major campaigns focused on the corporates, real food and transport.

\section{Internal structure}

The FoE (England and Wales - FoE Scotland operates as a separate group) network is comprised of the national office and 250 local groups. There are eight regional campaign co-ordinators. The local groups are encouraged to engage in actions of their own, to choose their own campaign priorities and to function as autonomous units. Local groups' reliance on FoE Ltd varies considerably, with some employing full-time staff. Membership at the national level has increased steadily since 1971, with a sharp increase in 1988-89, which then subsided; in the late 1990s numbers were stable. FoE relies on individual supporters' contributions for 96 per cent of its income, with the rest coming from fundraising events, sponsorship, grants and trading.

\section{Tactics}

FoE's strategy has been five-pronged:

1 political lobbying and legislative activity;

2 scientific research and information provision;

3 employing the media;

4 mobilising the public through local group activities and mass rallies;

5 co-ordinating and co-operating with other groups.

FoE's aversion to the use of illegal direct action, together with its emphasis on political lobbying, prevent it from being a radical environmental group.

\section{Green Student Network}

Formed late 1980s

\section{Aims}

To exchange information, debate environmental issues and facilitate local group actions.

\section{Internal structure}

GSN's organisational structure was very loose. Initially centred on British university 'green' groups, national gatherings and a newsletter produced by the coordinator, any structure that existed was fragmented in 1998. GSN effectively 
became less of a network with a strategic function and more a non-hierarchical collection of disparate individuals communicating via an email list. Participation was free and unregulated. Users simply sent an email to an specific address that automatically added them to the list. There was a high turnover of participants in the email list. GSN had no source of income.

\section{Tactics}

As GSN was not a campaigning group as such, it had no campaign tactics or priorities. However, certain topics on the email list were discussed more than others. The topics very much reflected the immediate concerns of British environmental politics.

\section{McSpotlight}

Launched 1996

\section{Aims}

To gather information that was critical of or damaging to McDonald's, and to make such material publicly available; to act as a network of support for all those (like the defendants in the McLibel trial) aiming to expose the operations of multinational corporations and to demonstrate that corporate attempts at censorship would fail.

\section{Internal structure}

The McInformation Network, a loose coalition of individuals, created the McSpotlight website. Many people joined in to do a small section of work or a specific task, and then left, while others continued to be involved through the peak of the website's popularity. The fifty contributors to the site were spread internationally, and email was used to help co-ordinate their efforts. Many of them have not met in person. McSpotlight was a collaborative but ad hoc endeavour, with a core of volunteers who tried not to dominate decisions about content. There was an attempt to organise along non-hierarchical lines. McSpotlight did not have a membership, but participants could sign up to email distribution lists or contribute to the debate forum. McSpotlight relied on donations and sales of its merchandise for its income.

\section{Tactics}

The tactic adopted by McSpotlight was to post anti-McDonald's information on its website for all to see. The McSpotlight website contained over 20,000 pages, with many different sections - about the McLibel trial, current issues, campaigning tools, a debating area, media coverage, court transcripts, interviews with key witnesses, and the libellous leaflet, translated into twenty languages, ready to print off. 


\title{
The Mobile Office
}

Formed 1997

\begin{abstract}
Aims
To provide activists in on-site protests with access to office facilities. Its various services included:

1 distributing information;

2 assisting with communications;

3 improving on-site safety;

4 acting as an information and resource centre;

5 recording events for archives.

The MO was run by a small group of volunteers, but, once the Office was on-site, others - from the protest camp and the locality - tended to become involved. MO attempted to organise non-hierarchically, though Pete, who spent the most time on the project, was often able to finalise decisions. The van and equipment were acquired on 'tat runs', ${ }^{2}$ or were donated or purchased using a grant.
\end{abstract}

\section{Tactics}

MO has been involved in several direct-action campaigns for which it provided the office equipment, communications technology and a resource base for activists.

\section{Save Westwood, Lyminge Forest}

Occupation began in 1997

\section{Aims}

To prevent the development of a holiday complex in Lyminge Forest.

\section{Internal structure}

The campaign was an organic direct-action protest, not an offshoot of an organisation or existing group. Non-hierarchical and decentralised forms of decisionmaking were practised, involving whatever participants were present. From March 1997 to the final months of 1999, 10-100 protesters lived in several camps situated across the development site. The protesters in the Forest relied on their personal income and on donations.

\section{Tactics}

Several tactics have been employed: their occupation of the site (which involved tunnelling, the building of towers and tree-houses, and using lock-ons) was an act of resistance to any attempts at clearing the Forest to build the holiday complex. 
Through this occupation and the associated media attention protesters sought to raise the public profile of the development proposals in order to increase support and put pressure on the local council and the Forestry Commission. They also undertook other direct actions, such as the occupation of Rank's boardroom. Finally, on some of their publicity flyers they encouraged people to write to their $\mathrm{MP}$ in support of the on-site action.

\title{
SchNEWS
}

Launched 1994

\begin{abstract}
Aims
To distribute the news which is ignored by the mainstream media. It is also anticopyright, encouraging readers to copy and re-distribute it themselves.

\section{Internal structure}

SchNEWS was run entirely by volunteers, roughly twenty-five people at any one time, in a non-hierarchical manner, using consensus decision-making and monthly review meetings to determine courses of action. A weekly timetable for activities and jobs to be done was established so that people knew when copy could be included in an issue and when different volunteers were required. New volunteers were continually sought, and training days arranged to impart the necessary skills to newcomers. Costs were covered by donations and subscriptions.
\end{abstract}

\section{Tactics}

Various tactics were employed to make SchNEWS' distribution as wide as possible - it was available via email; it was posted both on its website and via land-mail; and it was distributed by hand on the streets, at festivals and in bookshops. It encouraged other groups to copy and re-distribute SchNEWS' original material.

\section{Notes}

1 Information supplied by the groups themselves and in Anon. (1998d and 1999a), Atton (2000), Blue (1997), Frisch (1994), George (1999), Gibbs (2000), Greenberg (1985), Jenkins (1995), Krinks (1997), Lamb (1996), Lowe and Goyder (1983), McCormick (1995), Mills (1997), Pipes (1996), Rawcliffe (1998), Reed (1999) and Wapner (1995).

2 'Tat' refers to items which have been appropriated or recycled for free from a variety of sources, such as skips or building sites; in some cases the items were stolen. 